\title{
Genetic Association of Interferon Gamma Induced Protein-10 (IP-10), CXCL-10 Gene Polymorphisms with TB Pleurisy Susceptibility in South Indian Population
}

\author{
Ghousunnissa Sheikh' ${ }^{1}$, Venkata Sanjeev Kumar Neela' ${ }^{1}$, Satya Sudheer Pydi ${ }^{1}$, \\ Naveen Chandra Suryadevara1, Ramulu Gaddam², Suman Latha Gaddam ${ }^{3,4}$, \\ Sai Kumar Auzumeedi², Vijaya Lakshmi Valluri1,3*

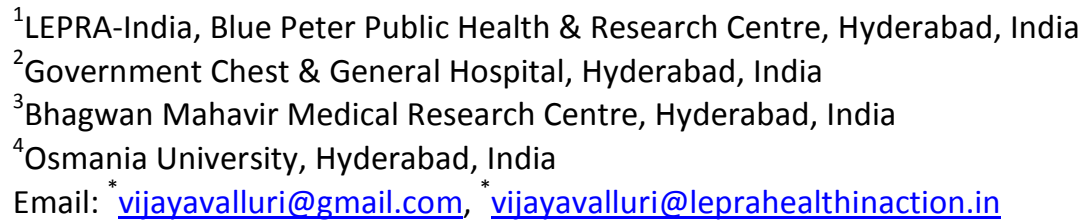

Received 12 December 2014; accepted 5 June 2015; published 9 June 2015

Copyright @ 2015 by authors and Scientific Research Publishing Inc.

This work is licensed under the Creative Commons Attribution International License (CC BY).

http://creativecommons.org/licenses/by/4.0/

(c) (i) Open Access

\section{Abstract}

$C X C L-10$ known as Interferon gamma-induced protein 10 (IP-10) or small-inducible cytokine 10 is a $8.7 \mathrm{kDa}$ protein, which is secreted in response to IFN- $\gamma$ by monocytes, endothelial cells and fibroblasts. It has chemo-attraction for monocytes/macrophages, $\mathrm{T}$ cells, $\mathrm{NK}$ cells and dendritic cells in promotion of $T$ cell adhesion to endothelial cells. In the present study, we investigated whether polymorphisms in $C X C L-10$ gene have any role in the manifestation of Tuberculous (TB) pleurisy. Two SNPs in $C X C L-10$ promoter region $(-1447 \mathrm{~A}>\mathrm{G}$ and $-135 \mathrm{G}>\mathrm{A})$ were genotyped in patients with TB Pleurisy $(n=186)$, Pulmonary TB patients $(n=159)$ and healthy controls $(n=205)$ by PCR-RFLP. Disease associations were statistically analyzed by Fisher exact test. At the -135G $>A$ position, the frequencies of genotype GA and allele $G$ were significantly high in TB pleurisy patients compared to healthy controls. While the frequencies of genotype AA and allele A were significantly low in TB pleurisy patients compared to healthy controls. The frequency of haplotype A-G with the combination of $1447 \mathrm{~A}>\mathrm{G}$ and $-135 \mathrm{G}>\mathrm{A}$ was significantly high in TB pleurisy. Our results reveal that genotype $\mathrm{GA}$ and allele $\mathrm{G}$ at $-135 \mathrm{G}>\mathrm{A}$ position were strongly associated with susceptibility to tuberculous pleurisy. The GA genotype may be a useful genetic marker for early detection of the disease in high risk individuals.

\footnotetext{
"Corresponding author.
}

How to cite this paper: Sheikh, G., et al. (2015) Genetic Association of Interferon Gamma Induced Protein-10 (IP-10), CXCL-10 Gene Polymorphisms with TB Pleurisy Susceptibility in South Indian Population. Open Journal of Immunology, 5, 72-78. http://dx.doi.org/10.4236/oji.2015.52008 


\section{Keywords}

\section{CXCL-10, Polymorphism, Haplotype, Susceptibility, Tuberculous Pleurisy}

\section{Introduction}

Tuberculosis (TB) is a major global public health problem in developing countries with an estimated 1.4 million deaths and 8.7 million new cases reported in 2011 [1]. Pulmonary TB is the most common form of TB, with extra-pulmonary tuberculosis accounting for $\sim 25 \%$ of adult cases, but this estimate increases to $~ 50 \%$ in high HIV prevalence settings [2]. Tuberculous (TB) pleurisy is the second most common form of extra-pulmonary tuberculosis after lymph node TB.

The occurrence of TB pleurisy is less than $1 \%$ of total exudative effusions in western countries out of which 3\% - 5\% corresponds to tuberculosis patients. However, in India, it is accountable for $30 \%-80 \%$ of all pleural effusions encountered and may complicate tuberculosis in 31\% of all cases [3] [4]. The first cells to encounter organisms invading the pleural space are mesothelial cells, which produce chemotactic molecules called chemokines, which are responsible for leukocyte activation and trafficking of cells for initiating inflammatory responses. Chemokines are low-molecular-weight chemotactic cytokines (8 - $14 \mathrm{kDa})$ that act through interactions with a subset of seven-transmembrane domain and G1protein-coupled receptors. There are 40 human chemokines, the majority of which are categorized as either $\mathrm{C}-\mathrm{X}-\mathrm{C}$ or $\mathrm{C}-\mathrm{C}$ chemokines based on the arrangement of the two N-terminal conserved cysteine residues in mammalian genomes [5]-[7]. C-X-C motif chemokine $10(C X C L-10)$ also known as Interferon gamma-induced protein 10 (IP-10) or small-inducible cytokine 10 is a $8.7 \mathrm{kDa}$ protein and located on human chromosome 4 in a cluster among several other CXC chemokines [8]. In response to IFN- $\gamma C X C L-10$ is secreted by monocytes, endothelial cells and fibroblasts. The principal function of $C X C L-10$ is chemoattraction of monocytes/macrophages, NK cells, T cells and dendritic cells. It also helps in promoting T cell adhesion to endothelial cells, antitumor activity, and angiogenesis [9] [10]. Earlier studies have revealed the association of gene polymorphisms with host susceptibility to various infectious diseases including TB [11]-[13]. Likewise the polymorphisms in chemokine genes were found to be associated with several autoimmune, infectious diseases including tuberculosis [14] [15].

$C X C L-10$ gene has been reported to play important role in the immune response to hepatitis and the innate immune response to respiratory tract pathogens including SARS, coronavirus and TB [16]-[18]. Recent studies have showed that chemokines are important as an early inflammatory mediator which determines the host immune response after exposure to pathogens. Tang et al. reported that polymorphism in the promoter region of $C X C L-10$ at $-135 \mathrm{G} / \mathrm{A}$ position was moderately associated with tuberculosis in Chinese population. The same variant was suggested to contribute to $C X C L-10$ gene expression by NF- $\mathrm{BB}$ transactivation [18]. Hence, we used a genetic association approach to study whether the variations in the promoter regions of $C X C L-10$ were associated with tuberculosis. The aim of the study was to investigate the association of CXCL-10 gene polymorphism (-1447 and -135$)$ with PTB and TB pleurisy.

\section{Subjects and Methods}

\subsection{Study Subjects}

A total of 345 patients of which 159 had pulmonary TB (PTB), 186 with TB pleurisy and 205 healthy ethnically matched, un-related controls of South Indian population were included in the study. Pulmonary Tuberculosis (mean age \pm SD: $43.8 \pm 6.99$ ) patients were registered at the Directly Observed Treatment Short course (DOTS) Clinics under the Revised National Tuberculosis Control program (RNTCP) centers at Bhagwan Mahavir Hospital \& Research Centre, Blue Peter Public Health and Research Center (BPHRC) India. Tuberculous pleurisy subjects (mean age \pm SD: $35.76 \pm 15.10$ ) were registered at Government General and Chest Hospital, Hyderabad, India. Healthy, asymptomatic subjects (mean age \pm SD: $42.36 \pm 20.14$ ) with no familial history of TB were included as controls for this study.

\subsection{Inclusion Criteria}

Newly diagnosed patients with no past history of TB or anti-tuberculosis treatment were enrolled. PTB patients 
were clinically confirmed by sputum smear acid-fast bacilli (AFB) staining and chest X-ray (CXR) and TB pleurisy patients were diagnosed based on Adenosine Deaminase (ADA) levels with a cut off $>40$, biopsy and fine-needle aspiration cytology (FNAC), protein RBS, radiological chest X Ray (CXR) and non-positivity in acid-fast bacilli (AFB) staining [19]. Healthy controls were asymptomatic individuals without any past history of TB or any other major illness. Peripheral blood was collected from the subjects after obtaining written informed consent and ethical guidelines practiced at the Chest hospital, Mahavir Hospital \& Research Centre and Blue Peter Research Centre (BPHRC). The study was approved by institutional ethical and biosafety committee.

\subsection{DNA Isolation}

DNA was extracted from whole blood using Flexigene DNA kit (cat no \# 51206) according to the manufacturer instructions (QIAGEN, Hilden, Germany). DNA concentrations were quantitated using nanodrop (ND-1000) spectrophotometer (Thermo scientifics, Wilmington, DE).

\subsection{Genotyping of CXCL-10 (IP-10) Gene}

Polymerase chain reaction (PCR) based restriction fragment length polymorphism (PCR-RFLP) was used for genotyping. Briefly, the reaction contained $100 \mathrm{ng}$ of genomic DNA, $10 \mathrm{pM}$ of specific primer along with $1 \mathrm{x}$ of Taq Master Mix (New England Biolabs) and adjusting the total volume to $25 \mu \mathrm{l}$ PCR reaction mixtures with water. The PCR was set in a programmable thermal cycler (Bio-Rad Thermo scientific CA). PCR conditions were: initial denaturation at $95^{\circ} \mathrm{C}$ for 5 min followed by 35 PCR cycles $\left[95^{\circ} \mathrm{C}\right.$ for $30 \mathrm{sec}, 60^{\circ}$ for $45 \mathrm{sec}, 72^{\circ} \mathrm{C}$ for $45 \mathrm{sec}$ ] and final extension at $72^{\circ} \mathrm{C}$ for $10 \mathrm{~min}$. The PCR product was used to perform the restriction enzyme digestion for 3 hrs with 1 unit of respective restriction enzymes (New England Biolabs, Inc, Ipswich, USA) at $37^{\circ} \mathrm{C}$ and the digested product was subjected to electrophoresis on $3 \%$ agarose gel for $45 \mathrm{~min}$ at $80 \mathrm{~V}$. The genotypes were determined based on product sizes compared to a $50 \mathrm{bp}$ ladder. The primer sequences, annealing temperatures for PCR, restriction enzymes and the restriction digestion patterns are mentioned in Table 1.

\subsection{Statistical Analysis}

The results were analyzed utilizing Open Epi Open Source Epidemiologic Statistics for Public Health software (version 2.2.1, Emory University and Rollins School of Public Health, GA). Disease associations were examined by uncorrected chi square $\left(\chi^{2}\right)$ and Fisher exact test. To determine Odds ratios (OR) with 95\% confidence interval the $2 \times 2$ cross-tabulation method was used. Hardy Weinberg equilibrium (HWE) testing was done using SNP stats online software and haplotyping was performed using the Haploview software (version 4.2). A p value of $\leq 0.05$ was considered statistically significant.

\section{Results}

\subsection{Single Nucleotide Polymorphisms IP-10-1447 Position}

The frequency of the homozygous GG genotype at -1447 position was significantly low in both PTB $(\mathrm{p}=0.04$, OR: 0.33, CI: $0.07-1.05)$ and in TB pleurisy ( $=0.007$, OR: 0.21, CI: $0.03-0.75)$ compared to healthy con-

Table 1. Primer sequences, PCR product and RFLP patterns for IP-10 genes.

\begin{tabular}{|c|c|c|c|c|c|}
\hline $\begin{array}{l}\text { polymorphisms } \\
\text { CXCL-10 }\end{array}$ & Sequences of the primers (5'-3'orientation) & $\begin{array}{c}\text { PCR } \\
\text { product } \\
\text { (bp) }\end{array}$ & $\begin{array}{c}\text { RE } \\
\text { enzymes }\end{array}$ & $\begin{array}{l}\text { Annealing } \\
\text { temp }\end{array}$ & $\begin{array}{c}\text { RFLP } \\
\text { pattern }\end{array}$ \\
\hline $\begin{array}{l}-1447 \mathrm{~A} / \mathrm{G} \\
\text { (rs4508917) }\end{array}$ & $\begin{array}{l}\text { F-TTGGTCAGGGAATGGAAAAG } \\
\text { R-CGGTTTCCCACAGCTAATTC }\end{array}$ & 290 & Sacl & 60 & $\begin{array}{c}\text { AA-290 } \\
\text { AG-290 + } 145 \\
\text { GG-145 }\end{array}$ \\
\hline $\begin{array}{c}-135 \mathrm{G} / \mathrm{A} \\
(\mathrm{rs} 56061981)\end{array}$ & $\begin{array}{l}\text { F-CCGTTCATGTTTTGGAAAGTGA } \\
\text { R-GGGAAGTCCCATGTTGCAGATT }\end{array}$ & 123 & BstBI. & 60 & $\begin{array}{c}\text { GG-123 } \\
\text { GA-123 + } 100 \\
\text { AA-100 }\end{array}$ \\
\hline
\end{tabular}

Nelsons tang et al. 2009. 
trols representing a negative association. The distribution of other homozygous AA, heterozygous AG genotypes, alleles A and G were similar in PTB and TB pleurisy groups compared to the healthy controls (Table 2).

\subsection{Single Nucleotide Polymorphisms IP-10-135 Position}

The frequency of the heterozygous GA genotype at -135 position was significantly high in both PTB $(\mathrm{p}=$ 0.0000001, OR: 3.48, CI: $2.18-5.56)$ and TB pleurisy ( $=0.0000004$, OR: 2.86, CI: $1.85-4.42)$ compared to healthy controls indicating a positive association. The homozygous AA genotype was significantly low in both TB pleurisy ( $<0.0000001$, OR: 0.20, CI: $0.11-0.37$ ) and PTB ( $=0.0000001$, OR: 0.10, CI: $0.04-0.22$ ) compared to healthy controls respectively, indicating a negative association. The frequency of allele $\mathrm{G}$ was significantly high in PTB ( $\mathrm{p}=0.0001$, OR: 1.79 , CI: 1.32 - 2.43) and TB pleurisy ( $=0.0009884$, OR: 1.60 , CI: 1.12 - 2.2) compared to healthy controls indicating a positive association, while the frequency of allele $A$ was significantly low in PTB ( $\mathrm{p}=0.0001$, OR: 0.56 , CI: $0.41-0.76)$ and in TB pleurisy ( $=0.0009$, OR: 0.62 , CI: 0.46 - 0.83) compared to healthy controls indicating a negative association (Table 3).

\subsection{Haplotype of IP-10 (-1447 and -135 Position) Gene}

On haplotype analysis ( -1447 and -135 polymorphisms) four combinations were observed. The frequency of haplotype with A-G combination was significantly high $(\mathrm{p}=0.003, \mathrm{p}=0.000006)$ in PTB and TB pleurisy; similarly the frequency of haplotype with A-A combination was significantly low $(p=0.001, p=0.02)$ in both PTB and TB pleurisy respectively. The haplotype combination $G-G$ frequency was significantly high $(p=0.02)$ in PTB alone whereas the frequency of haplotype combination G-A was significantly low $(p=0.02)$ in TB pleurisy respectively.

We observed that the frequency of A-G haplotype combination was over-representing in active pulmonary TB and TB pleurisy groups indicating their association with increased risk of developing these clinical forms of TB. The frequency of haplotype A-A combination appeared to be associated with resistance to pulmonary TB and TB pleurisy (Table 4).

\subsection{Hardy-Wein berg Equilibrium}

When the Hardy-Weinberg (HW) equilibrium test was performed, distribution of all genotypes in the healthy

Table 2. Frequency distribution of IP-10 (-1447 position) genotype. Genotype and allele frequencies of IP-10 ( -1447 position) gene polymorphisms.

\begin{tabular}{|c|c|c|c|c|c|c|c|c|c|}
\hline $\begin{array}{c}\text { Genotype } \\
\text { distribution }\end{array}$ & $\begin{array}{c}\text { AA vs } \\
\text { other }\end{array}$ & & & $\begin{array}{l}\text { AG vs } \\
\text { others }\end{array}$ & & & $\begin{array}{l}\text { GG vs } \\
\text { others }\end{array}$ & & \\
\hline $1447 A / G$ & n (\%) & p value & OR (CI) & n (\%) & $p$ value & OR (CI) & n (\%) & $p$ value & OR (CI) \\
\hline HC (205) & $90(43.9)$ & - & - & $100(48.7)$ & - & - & $15(7.3)$ & - & - \\
\hline TBpleurisy (186) & $90(48.4)$ & 0.43 & $\begin{array}{c}1.19 \\
(0.78-1.82)\end{array}$ & $93(50)$ & 0.88 & $\begin{array}{c}1.05 \\
(0.69-1.59)\end{array}$ & $3(1.6)$ & 0.01 & $\begin{array}{c}0.21 \\
(0.03-0.75)\end{array}$ \\
\hline PTB(159) & $62(39.0)$ & 0.40 & $\begin{array}{c}0.81 \\
(0.52-1.27)\end{array}$ & $93(58.4)$ & 0.08 & $\begin{array}{c}1.48 \\
(0.95-2.29)\end{array}$ & $4(2.5)$ & 0.04 & $\begin{array}{c}0.33 \\
(0.07-1.05)\end{array}$ \\
\hline ЕРTВ VS РTB & - & 0.08 & $\begin{array}{c}1.47 \\
(0.93-2.30)\end{array}$ & - & 0.11 & $\begin{array}{c}0.71 \\
(0.45-1.11)\end{array}$ & - & 0.55 & $\begin{array}{c}0.63 \\
(0.09-3.82)\end{array}$ \\
\hline Allele distribution & A (\%) & p value & OR (CI) & G (\%) & p value & OR (CI) & & & \\
\hline HC (410) & $280(68.3)$ & - & - & $130(31.7)$ & - & - & & & \\
\hline TB pleurisy (372) & $273(73.4)$ & 0.13 & $\begin{array}{c}1.28 \\
(0.92-1.77)\end{array}$ & $99(26.6)$ & 0.12 & $\begin{array}{c}0.78 \\
(0.56-1.08)\end{array}$ & & & \\
\hline РTB(318) & 217 (68.2) & 0.99 & $\begin{array}{c}0.99 \\
(0.72-1.38)\end{array}$ & 101 (31.8) & 0.99 & $\begin{array}{c}1.0 \\
(0.72-1.39)\end{array}$ & & & \\
\hline ЕРТВ VS РТВ & - & 0.14 & $\begin{array}{c}1.3 \\
(0.91-1.8)\end{array}$ & - & 0.14 & $\begin{array}{c}0.78 \\
(0.55-1.1)\end{array}$ & & & \\
\hline
\end{tabular}

All the comparisons are with Healthy control vs. Pulmonary and Pleurisy patients. Values are represented in (n). p value calculated by Chi-Square and value $\leq 0.05$ was considered significant. OR: odds ratio, CI: class intervals. HC: Healthy Controls, PTB: Pulmonary Tuberculosis, TBP: Tuberculous pleurisy. 
Table 3. Frequency distribution of IP-10 ( -135 position) genotype. Allele and genotype frequencies of IP-10 ( -135 position) gene polymorphisms.

\begin{tabular}{|c|c|c|c|c|c|c|c|c|c|}
\hline $\begin{array}{c}\text { Genotype } \\
\text { distribution }\end{array}$ & $\begin{array}{l}\text { GG vs } \\
\text { others }\end{array}$ & & & $\begin{array}{l}\text { GA vs } \\
\text { others }\end{array}$ & & & $\begin{array}{l}\text { AA vs } \\
\text { others }\end{array}$ & & \\
\hline 135 G/A & n (\%) & $p$ value & OR (CI) & n (\%) & p value & OR (CI) & n (\%) & $p$ value & OR (CI) \\
\hline HC (205) & 47 (22.9) & - & - & 88 (42.9) & - & - & 70 (34.1) & - & - \\
\hline $\begin{array}{c}\text { TB pleurisy } \\
\text { (186) }\end{array}$ & $41(22)$ & 0.93 & $\begin{array}{c}0.95 \\
(0.57-1.57)\end{array}$ & 127 (68.2) & 0.0000007 & $\begin{array}{c}2.86 \\
(1.85-4.42)\end{array}$ & $18(9.6)$ & $<0.0000001$ & $\begin{array}{c}0.20 \\
(0.11-0.37)\end{array}$ \\
\hline РТВ (159) & $36(22.6)$ & 0.99 & $\begin{array}{c}0.98 \\
(0.58-1.65)\end{array}$ & 115 (72.3) & $<0.0000001$ & $\begin{array}{c}3.48 \\
(2.18-5.56)\end{array}$ & $8(5)$ & $<0.0000001$ & $\begin{array}{c}0.10 \\
(0.04-0.22)\end{array}$ \\
\hline TBP VS PTB & - & 0.89 & $\begin{array}{c}0.96 \\
(0.56-1.66)\end{array}$ & - & 0.4 & $\begin{array}{c}0.82 \\
(0.50-1.34)\end{array}$ & & 0.1 & $\begin{array}{c}2.02 \\
(0.80-5.52)\end{array}$ \\
\hline $\begin{array}{c}\text { Allele } \\
\text { distribution }\end{array}$ & G (\%) & $p$ value & OR (CI) & A (\%) & $p$ value & OR (CI) & & & \\
\hline HC (410) & $\begin{array}{c}182 \\
(44.4)\end{array}$ & - & - & 228 (55.6) & & - & & & \\
\hline $\begin{array}{c}\text { TB pleurisy } \\
\text { (372) }\end{array}$ & $\begin{array}{c}209 \\
(56.18)\end{array}$ & 0.001 & $\begin{array}{c}1.60 \\
(1.19-2.15)\end{array}$ & $163(43.81)$ & 0.001 & $\begin{array}{c}0.62 \\
(0.46-0.83)\end{array}$ & & & \\
\hline РTB (318) & $\begin{array}{c}187 \\
(58.8)\end{array}$ & 0.0001 & $\begin{array}{c}1.79 \\
(1.31-2.43)\end{array}$ & 131 (41.19) & 0.0001 & $\begin{array}{c}0.55 \\
(0.41-0.76)\end{array}$ & & & \\
\hline TBP VS PTB & & 0.49 & $\begin{array}{c}0.89 \\
(0.66-1.23)\end{array}$ & & 0.49 & $\begin{array}{c}1.11 \\
(0.81-1.52)\end{array}$ & & & \\
\hline
\end{tabular}

All the comparisons are with Healthy control vs. Pulmonary and Pleurisy patients. Values are represented in (n). p value calculated by Chi-Square and value $\leq 0.05$ was considered significant. OR: odds ratio, CI: class intervals. HC: Healthy Controls, PTB: Pulmonary Tuberculosis, TBP: Tuberculous pleurisy.

Table 4. Haplotype combinations for IP-10 (-1447 and -135 position) polymorphisms. Haplotype frequencies of IP-10 gene polymorphisms in TB pleurisy and pulmonary TB. (a) TB pleurisy; (b) Pulmonary TB (PTB).

(a)

\begin{tabular}{ccccc}
\hline & \multicolumn{3}{c}{ TB pleurisy IP 10 } \\
\hline Haplotype & Frequency & Case ctrl ratio & Chi square & p value \\
\hline A - G & 0.358 & $0.421,0.302$ & 11.84 & 0.0006 \\
A - A & 0.355 & $0.314,0.392$ & 5.086 & 0.024 \\
G - A & 0.159 & $0.128,0.187$ & 4.91 & 0.026 \\
G - G & 0.128 & $0.137,0.120$ & 0.517 & 0.472 \\
\hline
\end{tabular}

(b)

\begin{tabular}{|c|c|c|c|c|}
\hline \multicolumn{5}{|c|}{ TB IP 10} \\
\hline Haplotype & Frequency & Case ctrl ratio & Chi square & $p$ value \\
\hline$A-A$ & 0.345 & $0.275,0.395$ & 10.76 & 0.001 \\
\hline$A-G$ & 0.344 & $0.406,0.299$ & 8.703 & 0.003 \\
\hline $\mathrm{G}-\mathrm{A}$ & 0.164 & $0.136,0.184$ & 2.859 & 0.090 \\
\hline$G-G$ & 0.148 & $0.183,0.123$ & 4.878 & 0.027 \\
\hline
\end{tabular}

p-value calculated by Chi-Square and value $\leq 0.05$ was considered significant. OR: odds ratio, CI: class intervals. PTB: Pulmonary Tuberculosis, TBP: Tuberculous pleurisy.

controls followed HW equilibrium ( $\mathrm{p}<0.05$ ). The $\mathrm{p}$ value for the position -1447 is $\mathrm{p}=0.07$ and for -135 is $\mathrm{p}=$ 0.06 . 


\section{Discussion}

Host genetic factors influence an individual response to infection with M. tuberculosis. These factors can possibly explain the susceptibility/resistance to the disease. Recent studies have shown that chemokines in addition to cytokines are crucial in mediating early inflammation which determines the host response after exposure to M. tuberculosis [20]. Since the polymorphisms studied (-1447\& $\&-135)$ in CXCL-10 gene are located in promoter region they may affect the gene expression or its function leading to impaired signaling which may further cause susceptibility to tuberculosis.

Our data suggests the homozygous genotype GG at -1447 position renders resistance to both PTB and TB pleurisy respectively. Contrastingly Tang et al. reported no association of -1447 loci with tuberculosis in Chinese population [18]. The disparity in association may be due to difference in ethnic groups and the complex etiology of the disease.

Our data indicates that the heterozygous GA genotype at -135 position may render susceptibility while homozygous AA genotype was offering resistance to both PTB and TB pleurisy respectively unlike, Tang et al.'s report that homozygous GA genotype and allele A was offering protection to TB in Chinese population [18]. Also allele $\mathrm{G}$ was rendering susceptibility to both PTB \& TB pleurisy which is in concordance with Deng et al. explaining allele $\mathrm{G}$ susceptibility to Hepatitis B virus infection [16].

The SNP-135 position is located 14 base pairs upstream of $C X C L-10$ gene, which has a binding site to $N F-k B$ and may also affect the transactivation effect of $N F-k B$ on $C X C L-10$ expression [18]. Therefore the genotype GA may play a crucial role in the genetic susceptibility to TB. Hence we conclude that individuals with GA genotype or $\mathrm{G}$ allele ( -135 position) and GG genotype ( -1447 position) may be vulnerable to PTB/TB pleurisy. Functional work based on allelic variants at these positions may provide further information on the mechanisms lying behind the susceptibility/disease progression which was one of the limitations of this study.

Our data reveals that the haplotype A-G, $(-1447,-135)$ might render susceptibility while A-A, G-A may offer resistance to TB pleurisy. While haplotype A-G, G-G may confer susceptibility and A-A may offer resistance to PTB respectively. Contrarily Nelson Tang et al reported haplotype G-A-G at $-1447,-872,-135$ positions to offer resistance with the disease [18]. To best of our knowledge, this is the first study to report $C X C L-10$ (IP-10) genotype and haplotype association with tuberculous pleurisy in south Indian population.

\section{Conclusion}

We demonstrate that the promoter polymorphisms $(-1447,-135)$ in $C X C L-10$ gene are associated with susceptibility to PTB and tuberculous pleurisy. The susceptible genotype GA, allele $G$ and haplotype A-G and G-G could be used as genetic marker to identify high risk individuals. However, there is a need to validate the results in larger cohort and in other populations.

\section{Acknowledgements}

The authors are thankful to The Department of Biotechnology (DBT), Government of India (BT/01/COE/07/02) for funding the project and LEPRA INDIA, Blue Peter public health \& Research Centre for providing facility and support. Also to R.S.S. Sharada and D.K. Prudhula for their valuable suggestions in manuscript preparation and all the participants in the study.

\section{Ethical Approval}

The study was approved by Institutional Ethical Committee (IEC).

\section{Funding}

Department of Biotechnology (DBT), Government of India (Grant No: BT/01/COE/07/02).

\section{Conflict of Interest}

The authors declare no conflict of interest. The funding agency had no role in the design of the study, collection and analysis of the data, or in the preparation of the manuscript. 


\section{References}

[1] World Health Organization (2012) WHO: Global Tuberculosis Report. WHO, Geneva, 100.

[2] Light, R.W. (2010) Update on Tuberculous Pleural Effusion. Respirology, 15, 451-458. http://dx.doi.org/10.1111/j.1440-1843.2010.01723.x

[3] Sharma, S.K. and Mohan, A. (2004) Extrapulmonary Tuberculosis. Indian Journal of Medical Research, 120, $316-353$.

[4] Udwadia, Z.F. and Sen, T. (2010) Pleural Tuberculosis: An Update. Current Opinion in Pulmonary Medicine, 16, 399406.

[5] Yoshie, O., Imai, T. and Nomiyama, H. (2001) Chemokines in Immunity. Advances in Immunology, 78, 57-110.

[6] Murdoch, C. and Finn, A. (2000) Chemokine Receptors and Their Role in Inflammation and Infectious Diseases. Blood, 95, 3032.

[7] Zlotnik, A. and Yoshie, O. (2000) Chemokines: A New Classification System and Their Role in Immunity. Immunity, 12, 121. http://dx.doi.org/10.1016/S1074-7613(00)80165-X

[8] O’Donovan, N., Galvin, M. and Morgan, J.G. (1999) Physical Mapping of the CXC Chemokine Locus on Human Chromosome 4. Cytogenetic and Genome Research, 84, 39-42. http://dx.doi.org/10.1159/000015209

[9] Dufour, J.H., Dziejman, M., Liu, M.T., Leung, J.H., Lane, T.E. and Luster, A.D. (2002) IFN-Gamma-Inducible Protein 10 (IP-10; CXCL10)-Deficient Mice Reveal a Role for IP-10 in Effector T Cell Generation and Trafficking. Journal of Immunology, 168, 3195-3204. http://dx.doi.org/10.4049/jimmunol.168.7.3195

[10] Angiolillo, A.L., Sgadari, C., Taub, D.D., Liao, F., Farber, J.M., Maheshwari, S., Kleinman, H.K., Reaman, G.H. and Tosato, G. (1995) Human Interferon-Inducible Protein 10 Is a Potent Inhibitor of Angiogenesis in Vivo. Journal of Experimental Medicine, 182, 155-162. http://dx.doi.org/10.1084/jem.182.1.155

[11] Hill, A.V. (2001) The Genomics and Genetics of Human Infectious Disease Susceptibility. Annual Review of Genomics and Human Genetics, 2, 373-400. http://dx.doi.org/10.1146/annurev.genom.2.1.373

[12] Hill, A.V. (2006) Aspects of Genetic Susceptibility to Human Infectious Diseases. Annual Review of Genetics, 40, 469-486. http://dx.doi.org/10.1146/annurev.genet.40.110405.090546

[13] Bellamy, R. (2006) Genome-Wide Approaches to Identifying Genetic Factors in Host Susceptibility to Tuberculosis. Microbes Infect, 8, 1119-1123. http://dx.doi.org/10.1016/j.micinf.2005.10.025

[14] Navratilova, Z. (2006) Polymorphisms in CCL2 \& CCL5 Chemokines/Chemokine Receptors Genes and Their Association with Diseases. Biomedical Papers, 150, 191-204. http://dx.doi.org/10.5507/bp.2006.028

[15] Smith, M.W., Dean, M., Carrington, M., et al. (1997) Contrasting Genetic Influence of CCR2 and CCR5 Variants on HIV-1 Infection and Disease Progression: Hemophilia Growth and Development Study (HGDS), Multicenter AIDS Cohort Study (MACS), Multicenter Hemophilia Cohort Study (MHCS), San Francisco City Cohort (SFCC), ALIVE Study. Science, 277, 959-965. http://dx.doi.org/10.1126/science.277.5328.959

[16] Deng, G., Zhou, G., Zhang, R., et al. (2008) Regulatory Polymorphisms in the Promoter of CXCL10 Gene and Disease Progression in Male Hepatitis B Virus Carriers. Gastroenterology, 134, 716-726. http://dx.doi.org/10.1053/j.gastro.2007.12.044

[17] Tang, N.L., Chan, P.K., Wong, C.K., et al. (2005) Early Enhanced Expression of Interferon-Inducible Protein-10 [CXCL-10] and Other Chemokines Predict Adverse Outcome in Severe Acute Respiratory Syndrome. Clinical Chemistry, 51, 2333-2340. http://dx.doi.org/10.1373/clinchem.2005.054460

[18] Tang, N.L., Fan, H.P., Chang, K.C., et al. (2009) Genetic Association between a Chemokines Gene CXCL-10 (IP-10, Interferon Gamma Inducible Protein 10) and Susceptibility to Tuberculosis. Clinica Chimica Acta, 406, 98-102. http://dx.doi.org/10.1016/j.cca.2009.06.006

[19] Gupta, B.K., Bharat, V. and Bandyopadhyay, D. (2010) Sensitivity, Specificity, Negative and Positive Predictive Values of Adenosine Deaminase in Patients of Tubercular and Non-Tubercular Serosal Effusion in India. Journal of Clinical Medicine Research, 2, 121-126. http://dx.doi.org/10.4021/jocmr2010.05.289w

[20] Moller, M. and Hoal, E.G. (2010) Current Findings, Challenges and Novel Approaches in Human Genetic Susceptibility to Tuberculosis. Tuberculosis (Edinb), 90, 71-83. http://dx.doi.org/10.1016/j.tube.2010.02.002 